\title{
AS CONTRIBUIÇÕES DO GESTOR ESCOLAR FRENTE AO PROCESSO INCLUSIVO EM ESCOLA REGULAR DO MUNICIPIO DE SIRINHAÉM - PE: PONTOS E CONTRAPONTOS
}

\author{
Ronalda Adriana dos Santos da Silva ${ }^{1}$ \\ Diógenes José Gusmão Coutinho ${ }^{2}$
}

\begin{abstract}
Resumo: A educação inclusiva se assenta na premissa basilar do contexto escolar como um espaço genuinamente diverso na sua composição de atores. $\mathrm{O}$ valor capital que cerca o processo inclusivo se consubstancia nos princípios constitucionais da igualdade e diversidade, entendidos como fundamentos perpétuos de uma tessitura social democrática e equânime. Neste contexto exposto, busca-se entender o papel desempenhado pelo gestor escolar na condução do labor pedagógico com vistas à implementação de uma práxis escolar indubitavelmente inclusiva e democrática. Assim, propõe-se como objetivo deste trabalho, investigar o processo inclusivo dos alunos em escolas de ensino fundamental e o aporte do gestor escolar para garantir uma prática pedagógica inclusiva e participativa entre todos os atores envolvidos nos espaços educativos. Para tanto, o método de abordagem utilizado foi um estudo de caso com uso da pesquisa qualitativa a partir da utilização de questionário aberto com perguntas respondidas pela comunidade escolar de uma unidade educacional da rede municipal de ensino do município de SirinhaémPernambuco.
\end{abstract}

Palavras-Chave: Diversidade. Educação inclusiva. Gestão democrática.

The contributions of the school manager to the inclusive process of regular school of the city of Sirinhaém -PE: items and counterpoints

Abstract: Inclusive education is based on the basic premise of the school context as a genuinely diverse space in its composition of actors. The capital value that surrounds the inclusive process is embodied in the constitutional principles of equality and diversity, understood as perpetual foundations of a democratic and equitable social fabric. In this context, we seek to understand the role played by the school manager in conducting the pedagogical work with a view to the implementation of undoubtedly inclusive and democratic school praxis. Thus, the objective of this work is to investigate the inclusive process of students in elementary schools and the contribution of the school manager to ensure an inclusive and participatory pedagogical practice among all actors involved in educational spaces. Therefore, the approach method used was a case study using qualitative research from the use of open questionnaire with questions answered by the

\footnotetext{
${ }^{1}$ Graduação curso de licenciatura plena em pedagogia - Universidade Estadual Vale do Acaraú, pósgraduação lato sensu em gestão e psicopedagogia institucional - faculdade européia de administração e marketing, mestranda internacional em ciências da educação, pela faculdade Atenas College University.Email: adriana-santos2011@ hotmail.com.br.

${ }^{2}$ Graduado em Biologia pela UFRPE. Doutor em Biologia pela UFPE. Professor do Mestrado em Direito pela ALPHA. E-mail: alphadiogenes@gmail.com.
} 


\section{Universidade do Extremo Sul Catarinense \\ Revista Ibero-Americana de Humanidades, Ciências e \\ Educação \\ unesc

school community of an educational unit of the municipal school system of the municipality of Sirinhaém-Pernambuco.

Keywords: Diversity. Inclusive Education. Democratic Management.

\section{INTRODUÇÃO}

A educação inclusiva se assenta na premissa basilar do contexto escolar como um espaço genuinamente diverso na sua composição de atores. Sob essa condição, é garantindo o acesso a todos os indivíduos no lócus educacional, respeitando as suas idiossincrasias. $\mathrm{O}$ valor capital que cerca o processo inclusivo se consubstancia nos princípios constitucionais da igualdade e diversidade, entendidos como fundamentos perpétuos de uma tessitura social democrática e equânime. Neste contexto exposto buscase entender o papel desempenhado pelo gestor escolar na condução do labor pedagógico com vistas a implementação de uma práxis escolar indubitavelmente inclusiva e democrática.

O objetivo deste trabalho é investigar o processo inclusivo dos alunos em escolas de ensino fundamental e o aporte do gestor escolar para garantir uma prática pedagógica inclusiva e participativa entre todos os atores envolvidos nos espaços educativos. Sendo os objetivos específicos: compreender as concepções dos docentes a respeito da inclusão; elencar os desafios cotidianos percebidos pelos docentes para garantir o processo inclusivo dos alunos com necessidades especiais e compreender o animus receptivo dos docentes e demais atores escolares no atendimento dos alunos com necessidades educacionais especiais.

O aporte teórico utilizado para compreender os meandros que cercam essa temática se consubstanciaram a partir de MITTLER (2003), Cury (2007), DRABACH e MOUSQUER (2009) e MAZZOTTA (2009), e concomitantemente a Constituição de 1988, Lei de Diretrizes e Bases da Educação Nacional e a Lei Brasileira de Inclusão da Pessoa com Deficiência. Sendo assim, este estudo balizou os aspectos teóricos sobre o tema e a averiguação factual em unidade escolar eleita como cenário desta pesquisa.

Para tanto, o método de abordagem utilizado foi um estudo de caso com uso da pesquisa qualitativa a partir da utilização de questionário com perguntas respondidas pela comunidade escolar de unidade educacional pertencente ao município de Sirinhaém- 


\section{Universidade do Extremo Sul Catarinense \\ Revista Ibero-Americana de Humanidades, Ciências e \\ Educação \\ unesc

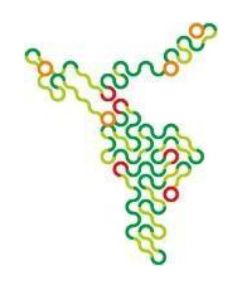

Pernambuco.

Dados divulgados pelo Instituto Nacional de Estudos e Pesquisas Educacionais (Inep) apontam um expressivo crescimento no acesso de estudantes com necessidades especiais nas escolas públicas e regulares do país na ordem de 33,2\% no hiato temporal entre 2014 e 2018. O mesmo levantamento revelou que em 2014 havia 87,1\% alunos pertencentes a essa modalidade de ensino, com idades entre 4 e 17 anos foram alocados em classes regulares. Esse número correspondeu a 92,1\% em 2018.

Esses dados são significativos sob o aspecto inclusivo, porém, hoje a discussão está para além da inclusão, e repousa na qualidade do ensino destinada aos alunos pertencentes à modalidade da educação especial. +Destarte, é necessário compreender que as transformações no aparelho educacional brasileiro estão atreladas a "[...] diversos fatores que envolvem o contexto político, social, econômico e cultural em que se insere a escola, as concepções e representações sociais relativas à deficiência e os recursos materiais disponíveis à escola". (MENDES, 2006, p.64).

\section{Díade: gestão democrática e os gestores escolares}

Dentro de uma perspectiva pautada pela administração escolar, "a educação no sentido macro é delineada na gestão educacional através das esferas públicas para atingir metas e objetivos no sistema educacional”. (DRABACH e MOUSQUER, 2009, p.131). Estas articulações entre os três níveis governamentais brasileiros. Uma das premissas sedimentadas nas políticas públicas que tratam da organização educacional se assenta na gestão democrática da escola que tem todo um percurso histórico para o ornato conceitual na atualidade.

As revisões literárias sobre a temática em tela albergam a crescente relevância investigativa que tem se acentuando a partir de 1990. Trabalhos realizados por (GRACINDO e WITTMANN 2001); (Pereira e Andrade 2005); (Souza 2006) reforçam a necessária aproximação entre gestão escolar às novas exigências atribuídas ao gestor escolar que ao tratar da qualidade do ensino se assenta na gestão democrática da escola como uma das condições para garantia de uma educação com vistas à qualidade.

A Carta Constitucional de 1988 figurou como produto final para o processo de redemocratização do Brasil essa condição trouxe como cenário escolar endógeno. 


\title{
Universidade do Extremo Sul Catarinense \\ Revista Ibero-Americana de Humanidades, Ciências e \\ Educação \\ UneSC Produção e democratização do conhecimento na lbero-América
}

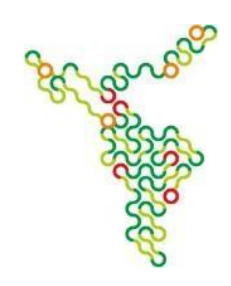

\begin{abstract}
A gestão democrática permite descentralizar o poder decisório de uma única pessoa para uma efetiva participação dos demais integrantes da comunidade escolar. O diretor que antes tinha como principal função fiscalizar, controlar e ditar os rumos dentro da escola se apresenta com um novo desafio, ser um mediador da escola frente aos anseios da sociedade onde está inserida. (FREITAS, 2016, p. 17).
\end{abstract}

Sendo um princípio, a gestão democrática está intimamente associada à aproximação com a qualidade educacional e recepção dos diversos atores na construção cotidiana da escola. Tendo o destaque legislativo:

\begin{abstract}
Os sistemas de ensino definirão as normas da gestão democrática do ensino público na educação básica, de acordo com as suas peculiaridades e conforme os seguintes princípios: I - participação dos profissionais da educação na elaboração do projeto pedagógico da escola; II - participação das comunidades escolar e local em conselhos escolares ou equivalentes. (CURY, 2007, p. 23).
\end{abstract}

Com vista aos princípios elencados pela Lei de Diretrizes e Bases da Educação, o lócus escolar deve estar em consonância com a coletividade e atendendo as prerrogativas legislativas constantes na Carta Constitucional de 1988 e no Plano Nacional de Educação (PNE).

A gestão democrática é vista como um princípio da educação pública brasileira, inclusive, obrigatória nas entidades escolares dos três níveis governamentais. É primal a sua presença para garantir uma comunidade escolar dialógica e participativa, e assim, apta para a elaboração e um projeto pedagógico com qualidade e que atenda as demandas dos atores que fazem parte da comunidade escolar. (CURY, 2007).

\footnotetext{
Os princípios existentes para que a gestão se torne democrática: participação, coletividade, autonomia e descentralização do poder. Portanto, não haverá gestão democrática sem a participação ativa de toda a comunidade escolar. Entende-se por comunidade escolar todos aqueles que de alguma forma contribuem e afetam a escola". (DRABACH e MOUSQUER, 2009, p.131).
}

Em sentido acordante as autoras (VELOSO e CRAVEIRO, 2012, p. 815), afiançam que a "[...] a participação da comunidade na vida escolar enquadra-se na noção de escola democrática". Factualmente o que se espera é uma ampla interação entre a comunidade escolar, com vista à participação cotidiana para construção junta de uma escola viva e dialógica.

Esse cenário democrático, participativo com um olhar ampliado acerca das 


\section{Universidade do Extremo Sul Catarinense \\ Revista Ibero-Americana de Humanidades, Ciências e \\ Educação \\ unesc

políticas públicas inclusivas. É uma das premissas da escola elaborar um sistema educacional que atenda as demandas individuais e respeite as diferenças de cada sujeito. "Essa escola luta pelos princípios da igualdade, liberdade, respeito e equidade com o objetivo de fortalecer a permanência das pessoas com necessidades educativas especiais no ensino regular". (VELOSO e CRAVEIRO, 2012, p. 815).

No somatório de competências de um gestor escolar alinhado com os ditames de uma gestão democrática, é necessário o caráter proativo da sua função e estão vigilantes as transformações sociais que têm um impacto no cotidiano escolar. A gestão democrática exige, segundo (SANDER, 1995, p. 135), “[...] um líder intelectual responsável pela coordenação do projeto pedagógico da escola, facilitando o processo coletivo de aprendizagem". Em complementação é dito que "[...] o gestor - representado pela figura do diretor - seria, primeiramente, o responsável pela condução do processo educativo, articulando ações para melhoria da qualidade das condições do contexto escolar". (ALONSO e MONTEIRO, 2009, p. 520).

\subsection{A comunidade escolar e o processo inclusivo no sistema educacional formal}

O processo inclusivo é vivenciado por toda a comunidade escolar, incluindo os prestadores de serviços, tais como porteiro e merendeiras. Cabe ao gestor criar estratégias formativas e sensibilizadoras para que todos façam parte desta ação inclusiva. Tacitamente é superada a visão que delimita o processo inclusivo às condições de acessibilidades e àqueles que trabalham nas salas com recursos multifuncionais. (SANTOS- LIMA, 2010, p. 54).

O educador em regência de classes regulares tem função preponderante frente ao processo inclusivo. Inicialmente preparando os alunos para compreender o caráter multifacetado e diversos dos sujeitos e as suas idiossincrasias, refletindo sobre as limitações de cada indivíduo diante do orbe social. E, concomitantemente, "[...] oferecendo ao aluno o direito de ser reconhecido como sujeito. Além disso, promover a aprendizagem e o desenvolvimento deste aluno, apesar das suas dificuldades pessoais, institucionais ou sociais". (SANTOS- LIMA, 2010, p. 54).

Sabe-se que, além da Sala de Recursos Multifuncional no espaço escolar, precisa-se de envolvimento de todos da comunidade escolar (professores, alunos, pais, funcionários) para que se possa efetivar a inclusão escolar. O 


\section{Universidade do Extremo Sul Catarinense \\ Revista lbero-Americana de Humanidades, Ciências e \\ Educação \\ Unesc Produção e democratização do conhecimento na lbero-América}

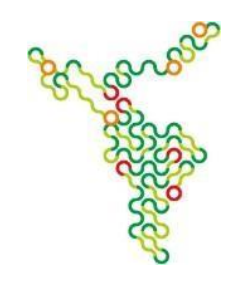

ambiente integrador de toda comunidade se dá através da participação de todos em prol dos objetivos propostos, efetivando-os nas ações coletivas ou individuais. (SANTOS- LIMA, 2010, p. 55).

As famílias pertencentes à comunidade escolar e o seu entorno são peças importantes para a efetividade do processo inclusivo. Vale a nota que o conceito de família que deve perdurar nos documentos escolares é entendimento compartilhado pela Carta Magna cunhada em 1988 que define como celular mater da sociedade composta por pessoas ligadas por laços de consanguinidades e/ou afetivos. Logo, "a família e a escola têm papéis fundamentais durante o desenvolvimento do sujeito, bem como no processo de inclusão, ambas são espaços de interações dos sujeitos com o meio". (CLOSS, 2015, p.8635). Portanto, a família é o espaço primal para as interações sociais e afetivas "[...] e o despertar de habilidades que, mais tarde, no espaço escolar, contribuirão no processo de aprendizagem e desenvolvimento do sujeito". (CLOSS, 2015, p.8636).

\section{0 percurso trilhado da exclusão à inclusão}

A educação para indivíduos com necessidades especiais é uma temática que alimenta inúmeros debates e, hoje responde por diversas conquistas. Há incontáveis avanços e distintos entraves que fazem da educação inclusiva um cenário que abriga a luta cotidiana por direito como bandeira centrica, já que, a educação para todos é um direito garantido pela Constituição brasileira. Anuindo, que a educação deve ser universal, no entanto, deve encontrar-se irmanada pelo princípio da qualidade. Dito de outra forma, a educação deve ser inclusiva, e com vistas, à qualidade do ensino.

No percurso histórico trilhado pelas pessoas com limitações tanto de ordem cognitiva, quanto sensorial ou física e sua inserção da conjuntura social da época foi feita de modo individual e descompassado, obedecendo aos preceitos sócios- históricos de cada época e espaço geográfico. $\mathrm{O}$ século $\mathrm{XX}$ apresenta um panorama significativo sobre essa condição quando verifica-se que indivíduos portadores de necessidades especiais “[...] foram submetidos a "experiências cientificas" na Alemanha nazista. Ao mesmo tempo, mutilados de guerra eram considerados heróis em países como os EUA, recebendo honrarias [...] do governo". (GARCIA, 2011).

A gênese do acolhimento para as pessoas com necessidades especiais é verificada inicialmente na Europa, e posteriormente se estende para a América do Norte com maior 


\title{
Universidade do Extremo Sul Catarinense \\ Revista Ibero-Americana de Humanidades, Ciências e \\ Educação \\ unesc

destaque nos estados Unidos. No Brasil, os primeiros registros históricos foram “[...] estabelecido no período final do século XIX, com a criação inspirada na experiência europeia do Instituto dos Meninos Cegos, em 1854, sob a direção de Benjamin Constant, e o Instituto dos Surdos-Mudos, em 1857”. (MAZZOTA, 2009, p.43).

\begin{abstract}
Até 1950, foram criados mais de cinquenta estabelecimentos no País que atendiam a pessoas consideradas deficientes. É importante salientar que o poder público nunca se ocupou, de fato, com a melhoria e ampliação da educação especializada, ficando tal responsabilidade a cargo da iniciativa privada. As duas entidades privadas que, com o passar do tempo, obtiveram um maior alcance nacional foram às sociedades Pestalozzi e as Associações de Pais e Amigos dos Excepcionais (APAEs) criadas nas décadas de 30 e 50, respectivamente que mantêm, até hoje, escolas especiais. (MAGALHÃES, 2002, p. 226).
\end{abstract}

$\mathrm{Na}$ atualidade, a educação é avalizada, segundo as palavras de (NOZU, ICASSATTI e BRUNO, 2017, 21), “[...] discurso pautado na sua responsabilização pelo desenvolvimento das pessoas, da comunidade e da sociedade, com potencial de preparação dos sujeitos para o exercício da cidadania e para a qualificação para o trabalho". Sendo assim, é um direito humano revestido de um supra princípio universal garantindo por preceitos jurídicos internacionais.

O compêndio jurídico nacional e internacional que tratam da educação reverbera para além de uma política pública “[...], mas como um direito que deve ser garantido e efetivado decorre de seu reconhecimento como uma "chave" para diversas portas, compreendida metaforicamente como um direito de acessibilidade a outros direitos". (NOZU, ICASSATTI e BRUNO, 2017, 22)

No mesmo sentido, (SACAVINO, 2007, p.457) afirma que é garantido que “[...] o direito à educação abre a porta para outros direitos, enquanto o seu desprezo traz consigo a negação de outros direitos e a perpetuação da pobreza". Essa condição se estabelece dada a primazia da educação para a sedimentação de diversos direitos. (SCHILLING, 2008).

Em atenção a essa perspectiva, adentra-se o palco das políticas tanto de cunho social quanto educacional com vistas ao melhoramento das suas condições de vida e sua completa inserção social. A Carta Constituinte afiança em seu art.205 a condição universal da educação, cita a educação especial no art. 208.

\footnotetext{
O dever do Estado com a Educação será efetivado mediante a garantia de: III - atendimento educacional especializado aos portadores de deficiência, preferencialmente na rede regular de ensino. (BRASIL,1998).
} 


\section{Universidade do Extremo Sul Catarinense \\ Revista Ibero-Americana de Humanidades, Ciências e \\ Educação \\ unesc

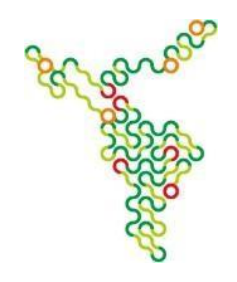

Com base fundada na Carta Política de 1988, a educação especial alça um novo patamar nas garantias dos direitos a atendimento especializado em classes regulares. Sendo assim, um direito público subjetivo, ficando o Estado obrigado a disponibilizar essa modalidade educacional que é tutelada expressamente pela normativa constitucional.

A educação especial sai da condição de educação segregada na Constituição de 1988 e renasce sob a batuta da inclusão dentro de uma conjuntura democrática.

Na conjuntura internacional a Declaração de Salamanca, elaborada em 1994 representa um marco decisivo para nortear as políticas educacionais, especialmente no Brasil. Esse documento, entre outras propostas, recomenda que "as crianças e jovens com necessidades educativas especiais devem ter acesso às escolas regulares, que a elas devem se adequar [...]", porquanto tais instituições "constituem os meios mais capazes para combater as atitudes discriminatórias, construindo uma sociedade inclusiva e atingindo a educação para todos [...]."

As Leis de Diretrizes e Bases da Educação dedica um capítulo para tratar das normativas sobre a educação especial.

Art. 58. Entende-se por educação especial, para os efeitos desta Lei, a modalidade de educação escolar, oferecida preferencialmente na rede regular de ensino, para educandos portadores de necessidades especiais. (...)

$\S 2^{\circ} \mathrm{O}$ atendimento educacional será feito em classes, escolas ou serviços especializados, sempre que, em função das condições específicas dos alunos, não for possível a sua integração nas classes comuns do ensino regular.

A educação especial ganha o status de modalidade, dito de outra forma, "a educação especial somente transcorre e complementa as etapas da Educação Básica e Superior, sendo considerada uma modalidade, e não constitui um nível de ensino". (MONTOAN, 2004, p. 68). Com vistas à efetivação do lócus educacional inclusivo contase com as salas de Recursos Multifuncionais, local que é ofertado Atendimento Educacional Especializado (AEE) a clientela atendida pela educação inclusiva. Para tanto, assente que a educação pública de qualidade deve ser redimensionada sob a perspectiva democrática para "[...] que flua e atinja a todos os alunos sem preconceitos, tornando a inclusão um processo natural, sem qualquer distinção cultural, social, étnico ou religioso". (MONTOAN, 2004, p. 68)

\section{Metodologia}

Sopesando a temática investigativa em tela, a pesquisa do tipo qualitativo que tem como foco a interpretação de um universo factual e os atores que transitam neste lócus. 


\section{Universidade do Extremo Sul Catarinense \\ Revista lbero-Americana de Humanidades, Ciências e \\ Educação \\ unesc

A pesquisa qualitativa tem como objetivo interpretar e dar significados aos fenômenos analisados. Nessa abordagem, os resultados não são traduzidos em números, unidades de medidas, ou categorias homogêneas de um problema [...]. (REIS, 2008, p. 57).

Foi elaborado e testado previamente o questionário aberto com 4 (quatro) perguntas referentes aos objetivos específicos o instrumento escolhido para a coleta de dados acerca do processo inclusivo. Sendo o questionário "um instrumento de coleta de dados, constituído por uma série ordenada de perguntas, que devem ser respondidas por escrito e sem a presença do entrevistador”. (MARCONI e LAKATOS, 2003, p. 201) Apoiado neste conceito os instrumentos foram aplicados.

Nos seus aspectos procedimentais referem-se a um estudo de caso que iniciou as suas investigações a partir da revisão de literatura e análise documental dos dispositivos legais que embasará as discussões a respeito dos achados investigativos encontradas no ambiente da pesquisa- Uma escola municipal com classes inclusivas no município de Sirinhaém/PE.

Deste modo, os caminhos procedimentais e metodológicos foram divididos em três etapas, a saber: a) levantamento bibliográfico e documental; b) organização, tratamento dos dados; c) apresentação dos resultados.

\section{Resultados e Discussões}

Cabe aqui fazer ponderações reflexivas acerca do olhar dos indivíduos que compõem a comunidade escolar a acerca da inclusão. O proposito inaugural deste espaço é conhecer as concepções do corpo docente, gestão e demais funcionários a respeito do processo inclusivo de crianças com necessidades especiais em classes regulares de uma dada escola municipal com alunos na etapa do ensino fundamental do município pernambucano de Rio Formoso. O questionário foi dividido por variáveis conceituais que giram em torno da temática em análise.

Sobre a categoria Preconceito e a Discriminação o docente $\left(\mathrm{D}^{1}\right)$ explica que com o tempo as pessoas se acostumam e param com o preconceito, e passa a aceitar a diferença que lhe parecerá (normal). Ademais, $\left(\mathrm{D}^{8}\right)$ explica que a “A questão da inclusão é aceitar as pessoas com suas limitações e que se deve respeitar as diferenças de cada pessoa". Ainda que a base legal nacional reforce a ideia de uma escola plural e heterogênea, a escola é um ambiente que emana um animus de preconceito, especialmente com os alunos com necessidades especiais. "O que acontece nas escolas é um reflexo da sociedade em 


\section{Universidade do Extremo Sul Catarinense \\ Revista Ibero-Americana de Humanidades, Ciências e \\ Educação \\ unesc

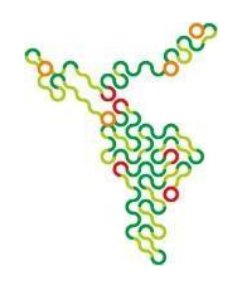

que elas funcionam”. (MITTLER, 2004, p,45).

Acerca da categoria inclusão é dito como $\left(\mathrm{C}^{1}\right)$ "a aceitação de criança com problemas diferentes, digo com necessidades especiais, primeiro na escola e depois na sociedade". Em posição semelhante $\left(\mathrm{C}^{3}\right)$ explica que "incluir significar integrar um aluno a uma realidade escolar". Aos sujeitos escolares, aqui representados por Colaborador (C) da escola em análise, mostra que ainda que fique evidenciado a sua compreensão acerca do processo inclusivo nas escolas, a fala retrata uma dissociação da vida escolar da sociedade circundante, sendo a escola uma representação e reflexo da tessitura social em microespaço vivacional. Em oposição ao pensamento que sinonimiza inclusão com integração é averbado que:

O processo de integração se traduz por uma estrutura educacional intitulada sistema de cascata, que oferece ao aluno a oportunidade, em todas as etapas de integração, de transitar no sistema escolar, da classe regular ao ensino especial. Trata-se de uma concepção de inserção parcial, porque a cascata prevê serviços segregados". (MONTOAN, 2004, p. 68).

Deste modo, fica inexplícito que a integração tem uma relação íntima com a segregação, já que, é previsto uma movimentação no sentido de adequação do aluno ao sistema vigente, porém, a inclusão parte do pressuposto da universalização de direitos em atendimento as suas especificidades.

Sobre os Direitos, a menção foi feita pelo $\left(\mathrm{C}^{5}\right)$ quando alude que "É um direito da criança ter acesso ao ensino, como toda criança tem [...] $\mathrm{O}$ fato de uma criança ser 'deficiente' não quer dizer que não tenha direito igual ao qualquer outra. É lei”. A Gestora (G) defende "Uma educação que seja pautada pelo direito à inclusão, viver em um país democrático exige que todos sejam atendidos pela lei, relação que exige obrigações, mas que também é baseada em direitos, não é diferente para os especiais".

Com vistas e essa categoria “(...) as pessoas e os grupos sociais têm o direito a ser iguais quando a diferença os inferioriza, e o direito de ser diferentes quando a igualdade os descaracteriza". (SANTOS, 2007, p. 30). Sendo assim, o direito à inclusão não pode ser entendido como mera formalidade jurídica é necessária à compreensão do direito à educação emancipatória, que prepare para a vida social e o mundo do trabalho.

Sobre a inserção das famílias no ambiente escolar e participante ativa das decisões escolares é anuído pelo $\left(\mathrm{D}^{5}\right)$ "a família precisa participar da vida escolar dos seus filhos, e digo mais, precisa agregar outros atendimentos médicos e terapêuticos aos seus filhos". 


\section{Universidade do Extremo Sul Catarinense \\ Revista Ibero-Americana de Humanidades, Ciências e \\ Educação \\ unesc

Com pensamento em igualdade $\left(\mathrm{D}^{2}\right)$ responde "as famílias são bem-vindas, mas o que percebemos é que um desafio para a escola trazer a família para dialogar e participar de modo colaborativo com a escola, só que é o contrário que ocorre".

É imprescindível acolher as famílias no interior das comunidades escolares, afirma (SANTOS, 2007, p. 31). "[...] e deve ser vista e tratada como um parceiro a mais no processo de quebra das barreiras que impedem a participação e a inclusão social de seus integrantes, por quaisquer motivos que sejam”. Logo, a família deve ser chamada à colaboração para o sucesso do processo inclusivo escolar, mais ainda, deve ser ouvida e atendida para que a escola seja eminentemente democrática.

Sobre a formação de professores em serviço é vista como um desafio cotidiano. "os educadores são despreparados para atenderem a clientela especial porque são muitas as demandas distintas destes alunos" $\left(\mathrm{C}^{5}\right)$. "Sinto que os professores que têm alunos especiais em sala ficam sobrecarregados e não estão preparados para lidar com essa clientela e as formações dadas pela escola ficam aquém das necessidades" $\left(\mathrm{D}^{3}\right)$.

Verifica-se em lócus que a inclusão atrelada a um continuum formativo que dê o devido suporte instrumental e pedagógico aos professores está em defasagem diante das demandas verificadas em sala de aula, porém, percebe-se, também, uma sinalização positiva quanto o processo de formação continuada da gestão escolar, ainda que exíguo diante da realidade vivenciada. Sendo assim, "é imprescindível um esforço tanto do corpo gerencial, pedagógico e dos colaboradores dá escola em oferecer uma melhor condição educativa, porém, sofremos de limitações tanto estruturais quanto de recursos". (G). A essa fala da gestora, é conferida uma preocupação no tocante á qualidade da educação oferecida a sua comunidade, uma das premissas da gestão escolar democrática.

Sobre o item gestão escolar laureada pelos ditames democráticos, a comunidade escolar fez sinalizações importantes. Duas categorizações foram utilizadas no apontamento investigativo, a saber:

O diálogo é o instrumento que melhor permite identificar os níveis de comprometimento dos gestores escolares com as bases democráticas de uma escola. É um mecanismo indispensável para a construção de um ambiente participativo. Sobre esse item foi dito que "a gestão democrática é quando uma escola adota uma postura de ouvir todo mundo, dos funcionários, os alunos, os professores e os pais dos alunos [...]. Isso 


\section{Universidade do Extremo Sul Catarinense \\ Revista Ibero-Americana de Humanidades, Ciências e \\ Educação \\ unesc

ocorre aqui na escola" $\left(C^{2}\right)$. Complementado pela fala do docente $\left(D^{4}\right)$, "Vejo uma preocupação da gestora em acolher as demandas de toda a comunidade. Aqui, há uma escuta sensível". A gestora explica essa preocupação ao afirmar que "Uma escola viva pautada pelas regras que são próprias da democracia dele eleger o diálogo como forma de uma construção coletiva em que os direitos e deveres de todos sejam sempre respeitados" $(\mathrm{G})$

É através da participação dialógica que os sujeitos ganham voz e se instrumentalizam para replicar suas vivencias escolares nas mais diversas esferas da vida social. Compete à escola exercitar cotidianamente o diálogo como o passo inicial para a construção do ambiente democrático e interativo.

Sobre o item Participação efetiva da comunidade escolar foi citada pela colaboradora $\left(\mathrm{C}^{1}\right)$ que a elaboração da Proposta Pedagógica (PP) "foi construída e a escola estava presente, só que ficamos presos à lei, e as questões da nossa comunidade que a lei não trata? A escola também não vai tratar?”. Sobre a participação dos docentes na construção do Projeto Político Pedagógico que "representa a essência da escola e a participação de todos é fundamental para garantir uma escola dialógica” $\left(\mathrm{D}^{7}\right)$. "O projeto pedagógico, ao se constituir em processo participativo de decisões, preocupa-se em instaurar uma forma de organização do trabalho pedagógico que desvele os conflitos". Retroalimentar o PP da escola é antecipadamente buscar caminhos para dirimir as relações competitivas, privilegiando a construção de relações horizontais entre todos os atores que transitam no universo escolar. (VEIGA, 2004, p.96).

\section{Considerações finais}

A premissa investigativa desta pesquisa está relacionada com a problemática acerca do processo inclusivo dos alunos em escolas de ensino fundamental e o aporte do gestor escolar para garantir uma prática pedagógica inclusiva e participativa entre todos os atores envolvidos nos espaços educativos, sendo o ambiente da pesquisa escola regular do ensino fundamental com salas inclusiva no município de Sirinhaém, que fica localizado no litoral sul de Pernambuco.

A investigação em tese buscou apresentar os marcadores teóricos acerca da inclusão e o papel da gestão neste processo respaldado por uma investigação factual que 


\section{Universidade do Extremo Sul Catarinense \\ Revista Ibero-Americana de Humanidades, Ciências e \\ Educação \\ unesc

permitiu a junção teoria e práxis. Adentrar uma unidade escolar e perceber nas falas dos seus autores, em especial da gestão acerca do processo inclusivo, torna-se um convite para refletir acerca da importância do papel do gestor escolar frente à problemática inclusiva.

Diante das teorizações e resultados apresentados é possível afiançar que o comprometimento gerencial no espaço educacional é preponderante para que a comunidade escolar com todos os seus protagonistas esteja inserida em um espaço dialógico.

Observa-se que a escola eleita para essa investigação está caminhando timidamente para garantir um processo axiomaticamente democrático, porém, percebe-se a construção de uma caminhada que culmine em uma escola democrática e inclusiva. A gestão escolar desenha, em sua fala, as percepções acerca da necessidade de aglutinar a comunidade escolar para construção de uma escola participativa e que atenda as idiossincrasias dos alunos com necessidades especais, mas que seja inclusiva para todos independente de credo, cor, idade, posição político e filosófica.

Ainda que de maneira tímida seja percebida a sensibilização dos docentes e demais funcionários acerca da necessidade do processo inclusivo, inclusive sob o aspecto legal. Evidencia-se, também, a ideia da responsabilidade escolar, com todos os seus membros na garantia de uma educação inclusiva e democrática. Não restringindo aos professores que têm alunos com necessidades especiais em suas classes. Essa condição de entendimento acerca da escola inclusiva é de grande valia, já que, o sentimento de pertencimento e responsabilidade deve ser a tônica para uma educação com qualidade. É cogente que a gestão escolar, também, seja uma gestão escolar democrática.

Isto posto, essa investigação não teve como escopo entrever as deficiências e limitações da entidade educativa pesquisada, no entanto, o intento é criar oportunidades de reflexivas acerca da díade gestão escolar e o processo inclusivo, dado o caráter do processo educativo que é pontilhado por demandas, discussões e pesquisas.

\section{REFERENCIAS}

ALONSO, Kátia Morosov e Monteiro, Tereza Leones. "O Gestor Escolar e a Gestão Democrática: papéis e desafios. R. Educ. Públ. Cuiabá, 2009. 


\section{Universidade do Extremo Sul Catarinense \\ Revista Ibero-Americana de Humanidades, Ciências e \\ Educação

unesc

BRASIL, Constituição da República Federativa do Brasil. Brasília, 1988. Disponível em: <http://www.planalto.gov.br/ccivil_03/constituicao/constituicao.htm>

Instituto Nacional de Estudos e Pesquisas Educacionais. Censo Escolar 2018.

Disponível: $<$ http://portal.inep.gov.br/artigo/-

/asset_publisher/B4AQV9zFY7Bv/content/censo-escolar-2018-revela-crescimento-de-

18-nas-matriculas-em-tempo-integral-no-ensino-medio/21206 >

Declaração de Salamanca. (grifo nosso). Disponível em:

<http://portal.mec.gov.br/seesp/arquivos/pdf/salamanca.pdf >

CLOSS, Keula Maqueli, “UM DIÁLOGO SOBRE A INCLUSÃO A PARTIR DA

GESTÃO ESCOLAR E SEUS ATORES”. In Revista Formação de Professores,

Complexidade e trabalho Docente. Vol:1. Anais do Congresso Nacional de Educação-

EDUCERE, PUCPR/UNESCO, 2015.

CURY, Carlos Roberto Jamil, "A gestão democrática na escola e o direito à educação", Revista Brasileira de Política e Administração da Educação, vol: 23 num 3, 2007.

DRABACH, Neila Pedrotti e MOUSQUER, Maria Elisabeth Londero. Currículo sem fronteiras. Santa Maria, RS: UFSM, 2009.

GARCIA, Vinicius Gaspar. As pessoas com deficiência na história do mundo. 2011.

Disponível em: 〈http://www.bengalalegal.com/pcd-mundial>

FREITAS, José Cristiano Lima de. A CONSTITUIÇÃO E A GESTÃO DEMOCRÁTICA NA ESCOLA BRASILEIRA. Revista PLUS FRJ: Revista Multidisciplinar em Educação e Saúde, num 2, 2016. Disponivel: $<$ https://www.faculdadeplus.edu.br/wpcontent/uploads/2016/11/02-Artigo-A-CONSTITUI\%C3\%87\%C3\%83O-E-A-

GEST\%C3\%83O-DEMOCR\%C3\%81TICA-NA-ESCOLA-BRASILEIRA.pdf>.

MAGALHÃES, Rita de Cássia Barbosa Paiva. Reflexões sobre a diferença: uma introdução à educação especial. (Fortaleza: Edições Demócrito Rocha, 2002): 226.

MARCONI, Marina de Andrade e LAKATOS, Eva Maria. Fundamentos de metodologia científica.5. Ed. São Paulo: Atlas, 2003.

MAZZOTTA, Marcos. Educação Especial no Brasil: História e Políticas Públicas. São Paulo: Cortez Editora, 2009.

MENDES, Enicéia Gonçalves. A radicalização do debate sobre inclusão escolar no Brasil. Revista Brasileira de Educação, Rio de Janeiro, 2006.

MONTOAN, Maria Tereza Eglér. A integração de pessoas com deficiência. Contribuições para uma reflexão sobre o tema. São Paulo: Memnon, 2004.

NOZU, Washington Cesar Shoiti; ICASATTI, Albert Vinicius e BRUNO, Marilda Moraes Garcia. Educação inclusiva enquanto um direito humano. Revista Inc.Soc, Brasília, 2017. 


\section{Universidade do Extremo Sul Catarinense \\ Revista Ibero-Americana de Humanidades, Ciências e \\ Educação \\ Unesc Produção e democratização do conhecimento na lbero-América}

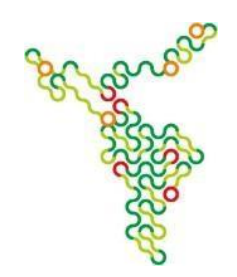

REIS, Linda, Produção de Monografia: Da teoria à prática. O método educar pela pesquisa (MEP), Editora SENAC. Distrito Federal, 2008.

SANDER, Benor. Gestão da Educação na América Latina: construção e reconstrução do conhecimento. Campinas: autores associados, 1995.

SANTOS- LIMA, Helen Tatiana. O papel do professor no contexto inclusivo: uma reflexão a partir da teoria da subjetividade. e-Revista Facitec, vol: 4: num1, 2010.

Santos, Boaventura de Sousa, "Uma concepção multicultural de Direitos Humanos". Lua Nova Revista de Cultura e Política. Governo e Direitos - CEDEC, 2007.

SCHILLING, Flávia. O direito à educação: um longo caminho. In: BITTAR, E. C. B. (Org.). Educação e metodologia para os direitos humanos, São Paulo: Quartier Latin, 2008.

VELOSO, Luísa; CRAVEIRO, Daniela; RUFINO, Isabel. Participação da comunidade educativa na gestão escolar", Revista Educação e Pesquisa: São Paulo,2012.

VEIGA, Ilma Passos Alencastro. Educação básica e educação superior: projeto políticopedagógico, Campinas: Papirus, 2004. 